\title{
Relato de experiências na (des) organização e compartilhamento de materiais didáticos digitais
}


necessidades $x$ ações paliativas:

\section{Disciplinas de Graduação OAs como material de apoio para a modalidade presencial}

Arquivos espalhados em computadores dos professores e monitores Gravação de cds, pendrives... Site com os materiais (problemas de atualização) Postura do improviso, revisão, novas estratégias de aprendizagem Ambientes virtuais de aprendizagem como apoio ao presencial Disponibilização das trajetórias de ensino aprendizagem (Cmaptools) 
Relato de experiências na (des) organização e compartilhamento de materiais didáticos digitais

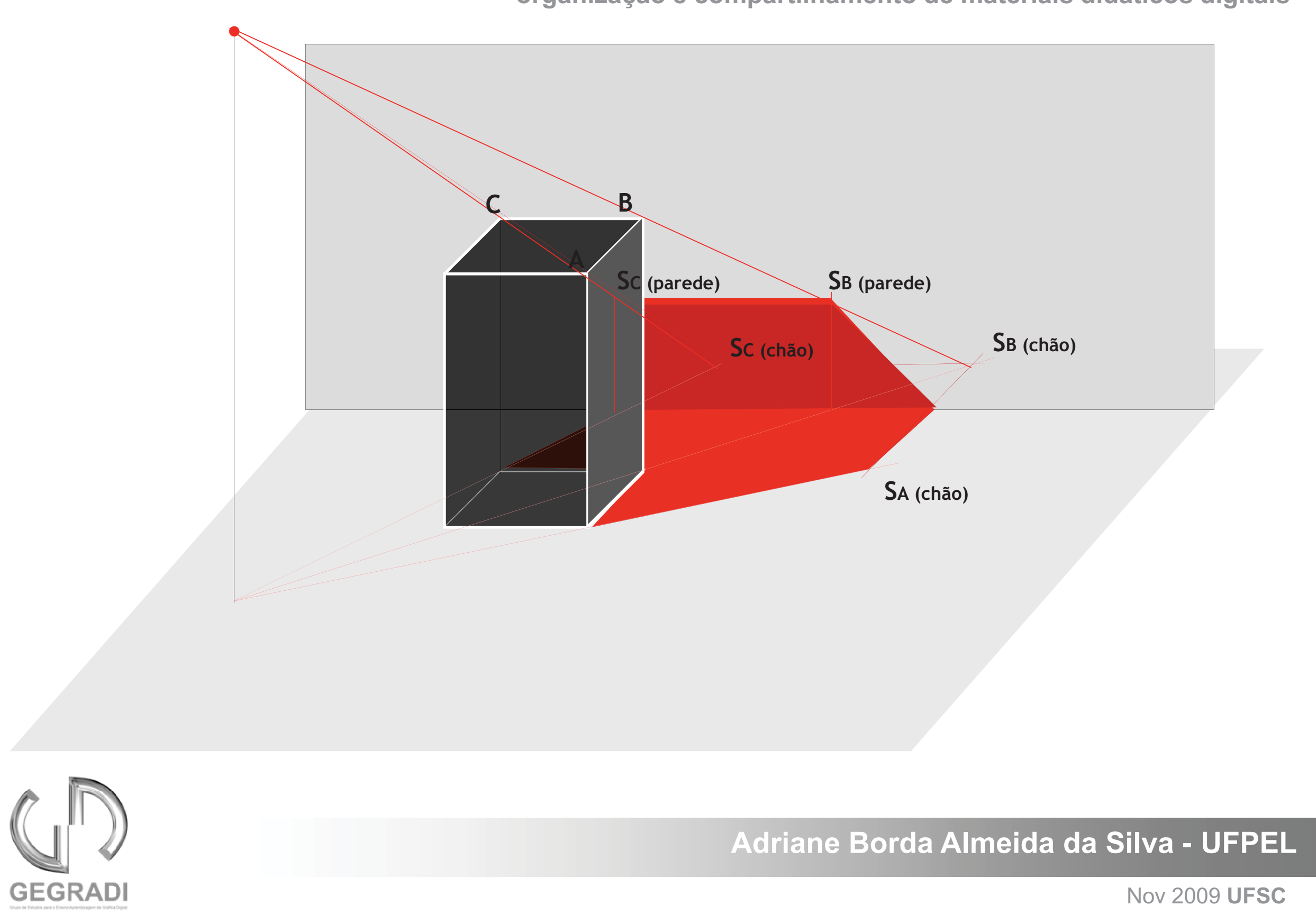



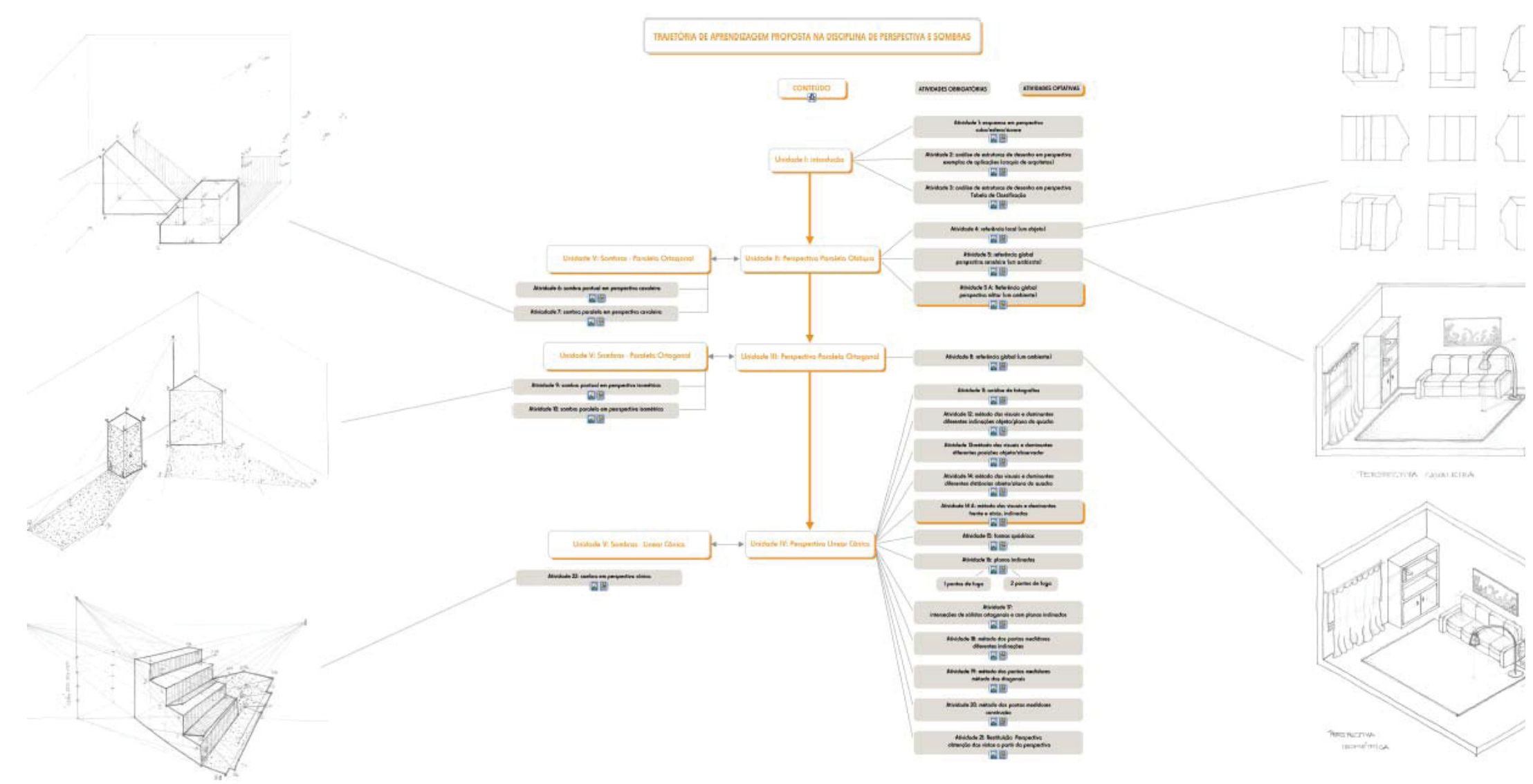
necessidades $x$ ações paliativas:

\section{Curso de Pós-graduação Modalidade compartilhada (estudantes a distância)}

ampliação de toda a problemática vivenciada no âmbito de disciplinas estruturação do @GD proposta de ambiente colaborativo (validação dos objetos) investimento na formação de agentes para a EAD reflexões sobre a caracterização dos materiais didáticos como objetos de aprendizagem delimitação de metadados de domínio 


\section{(C) CD Ambiente de RepositóRio de OBjetos de Aprendizagem Gráfica Digital}

Objetos de Aprendizagem no padrão Doublin Core

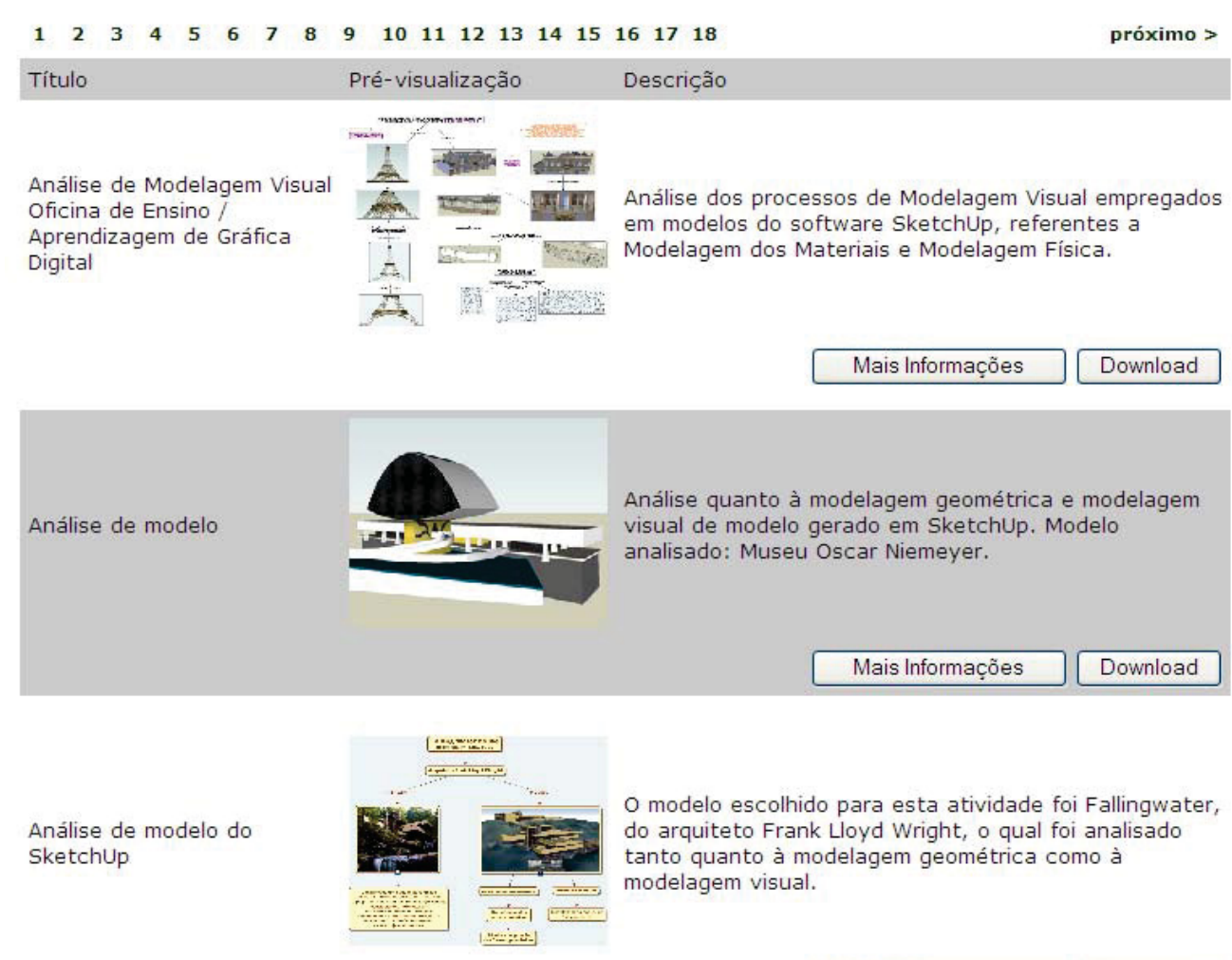

Mais Informações Download

\section{Adriane Borda Almeida da Silva - UFPEL}




\begin{tabular}{|c|c|}
\hline \multicolumn{2}{|r|}{ Inserção de Objetos no @GD } \\
\hline * Metadados & **preenchimento dos campos \\
\hline Inserir objeto: & $\begin{array}{l}\text { Quando o objeto contiver mais de um arquivo será necessário } \\
\text { compor uma única pasta compactada, como acontece com arquivos } \\
\text { no formato html que contém imagens. }\end{array}$ \\
\hline Título: & $\begin{array}{l}\text { No modo de visualização da lista de objetos de aprendizagem o } \\
\text { titulo aparecerá ao lado de uma imagem significativa do objeto e } \\
\text { também de sua descrição. De qualquer forma, o titulo deverá conter } \\
\text { palavras chaves que caracterizem o objeto para permitir, } \\
\text { futuramente, a localização deste objeto por um sistema de busca } \\
\text { automatizado. }\end{array}$ \\
\hline Descrição: & $\begin{array}{l}\text { A descrição deverá ser sucinta, acrescentando informações que os } \\
\text { metadados não estão sendo capazes de explicitar. Por exemplo: } \\
\text { material de apoio a uma situação didática síncrona ou presencial } \\
\text { referente ao conceito de modelagem de formas livres, a partir do } \\
\text { modelo NURBS (conceito matemático deste modelo) }\end{array}$ \\
\hline $\begin{array}{l}\text { Imagem do } \\
\text { Objeto: }\end{array}$ & $\begin{array}{l}\text { Quando o disponibilizador considerar que não existe uma imagem } \\
\text { significativa, capaz de caracterizar o objeto, aparecerá o logotipo } \\
\text { deste repositório (@gd) }\end{array}$ \\
\hline Autor: & $\begin{array}{l}\text { Nome do autor do objeto de aprendizagem, grupo e instituição a } \\
\text { qual pertence, cargo ou função }\end{array}$ \\
\hline Assunto: & $\begin{array}{l}\text { Identificar o(s) tópico(s) ou unidade(s) de estudo da Gráfica Digital } \\
\text { que este objeto se insere (s). Exemplo: Modelagem Geométrica, } \\
\text { Representação de Formas Livres ou Paramétricas }\end{array}$ \\
\hline Disponibilizador: & $\begin{array}{l}\text { Nome do disponibilizador do objeto de aprendizagem, neste } \\
\text { ambiente, grupo e instituição a qual pertence, cargo ou função }\end{array}$ \\
\hline Contribuição: & $\begin{array}{l}\text { Quando houver, indicar nome de pessoas ou grupos, que tenham } \\
\text { colaborado com a estruturação ou reestruturação do objeto de } \\
\text { aprendizagem (local onde se pode registrar a evolução do objeto, } \\
\text { quando forem editadas diferentes versões) }\end{array}$ \\
\hline Data: & $x x / x x / x x x x$ \\
\hline Tipo: & $\begin{array}{l}\text { Explicitar questões pedagógicas que possam caracterizar o objeto: } \\
\text { Teoria, Tecnologia, Técnica, Problema, Tutorial, Expositivo, Analítico, } \\
\text { Descritivo, Jogo,... ou composiçôes destas categorias }\end{array}$ \\
\hline
\end{tabular}

\begin{tabular}{|c|c|}
\hline Formato: & $\begin{array}{l}\text { Extensão do arquivo digital (doc, html, pdf, ppt,...), devendo esta } \\
\text { informação ser acrescida de especificaçós como: video, texto, } \\
\text { animação,... e das ferramentas informáticas necessárias para } \\
\text { utilizaçăa do objeto }\end{array}$ \\
\hline Fonte: & $\begin{array}{l}\text { Devem ser especificadas as fontes de textos, gráficos e imagens } \\
\text { utilizadas para compor o objeto de aprendizagem, quando não } \\
\text { forem de autoria do próprio autor do objeto. Esta especificação deve } \\
\text { estar neste campo e também registrada junto ao próprio objeto }\end{array}$ \\
\hline Linguagem: & $\begin{array}{l}\text { Especificar a língua em que está estruturado o objeto (português, } \\
\text { inglês, espanhol,...) }\end{array}$ \\
\hline Relação: & $\begin{array}{l}\text { Indicar os objetos de aprendizagem, já cadastrados neste } \\
\text { repositório, que se relacionam com este objeto }\end{array}$ \\
\hline Abrangência: & $\begin{array}{l}\text { Identificar o(s) tópico(s) ou unidade(s) de estudo da Gráfica Digital } \\
\text { que este objeto pode ser relacionado (s). }\end{array}$ \\
\hline Direitos: & Indicar a quem pertence os direitos autorais do objeto \\
\hline Audiência: & $\begin{array}{l}\text { Especificar o público alvo para o qual este objeto foi gerado. Por } \\
\text { exemplo: nivel médio, técnico ou superior de ensino, podendo ser } \\
\text { citadoo o contexto específico (Curso de Especialização em Gráfica } \\
\text { Digital, Disciplina de Modelagem Geométrica) }\end{array}$ \\
\hline $\begin{array}{l}\text { Tipo de } \\
\text { interatividade: }\end{array}$ & $\begin{array}{l}\text { Descrição do tipo de interação solicitada para o uso do objeto, } \\
\text { incluindo a especificação de interfaces necessárias para este uso. }\end{array}$ \\
\hline $\begin{array}{l}\text { Nivel de } \\
\text { interatividade: }\end{array}$ & $\begin{array}{l}\text { Alto, médio e baixo: parâmetros de referência a serem } \\
\text { estabelecidos, conforme a caracterizaçăo proposta para cada objeto. }\end{array}$ \\
\hline $\begin{array}{l}\text { Tempo médio de } \\
\text { aprendizagem: }\end{array}$ & $\begin{array}{l}\text { A especificação do tempo de aprendizagem deve estar associada a } \\
\text { um contexto concreto de uso ou de experimentação. }\end{array}$ \\
\hline Método de ensino: & $\begin{array}{l}\text { Descrição da metodologia implíita ao material: Resolução de } \\
\text { problemas, construtivista, ,... }\end{array}$ \\
\hline $\begin{array}{l}\text { Nivel de } \\
\text { Granularidade: }\end{array}$ & $\begin{array}{l}\text { Alto (um conceito, um problema, uma técnica,...), médio (um tópico } \\
\text { de disciplina, um conteúdo) e baixo (Um Curso, uma disciplina). } \\
\text { Para que se estabeleçam parâmetros de referência para este } \\
\text { metadado, na área de Gráfica Digital, solicita-se uma breve } \\
\text { descrição da possibilidade de decomposição do objeto em objetos } \\
\text { menores, para que o usuário possa vislumbrar o reaproveitamento } \\
\text { em diferentes contextos educativos. }\end{array}$ \\
\hline
\end{tabular}


necessidades $x$ ações paliativas:

Curso profissionalizante Modalidade a distância OAs com granularidade muito baixa, organizados diretamente nos ambientes de aprendizagem

Curso de graduação (UAB) Modalidade a distância urgência em soluções mais duradouras 




\section{Adriane Borda Almeida da Silva - UFPEL}


Outras experiências na área de domínio... Outros tipos de repositórios...

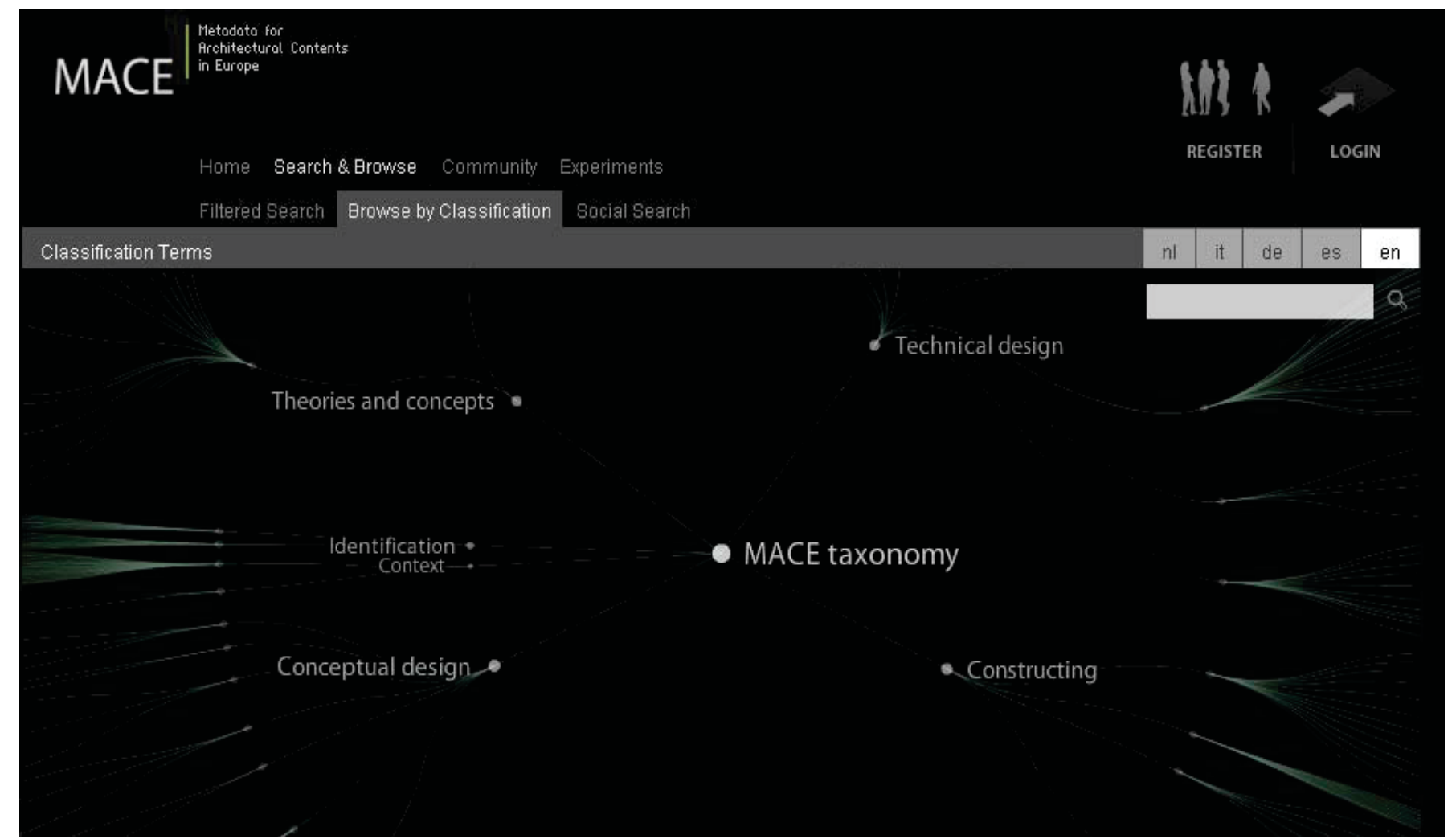

Parte da taxonomia do MACE esta baseada no repertõrio "Art \& Architecture Thesaurus (AAT)". (Getty) 


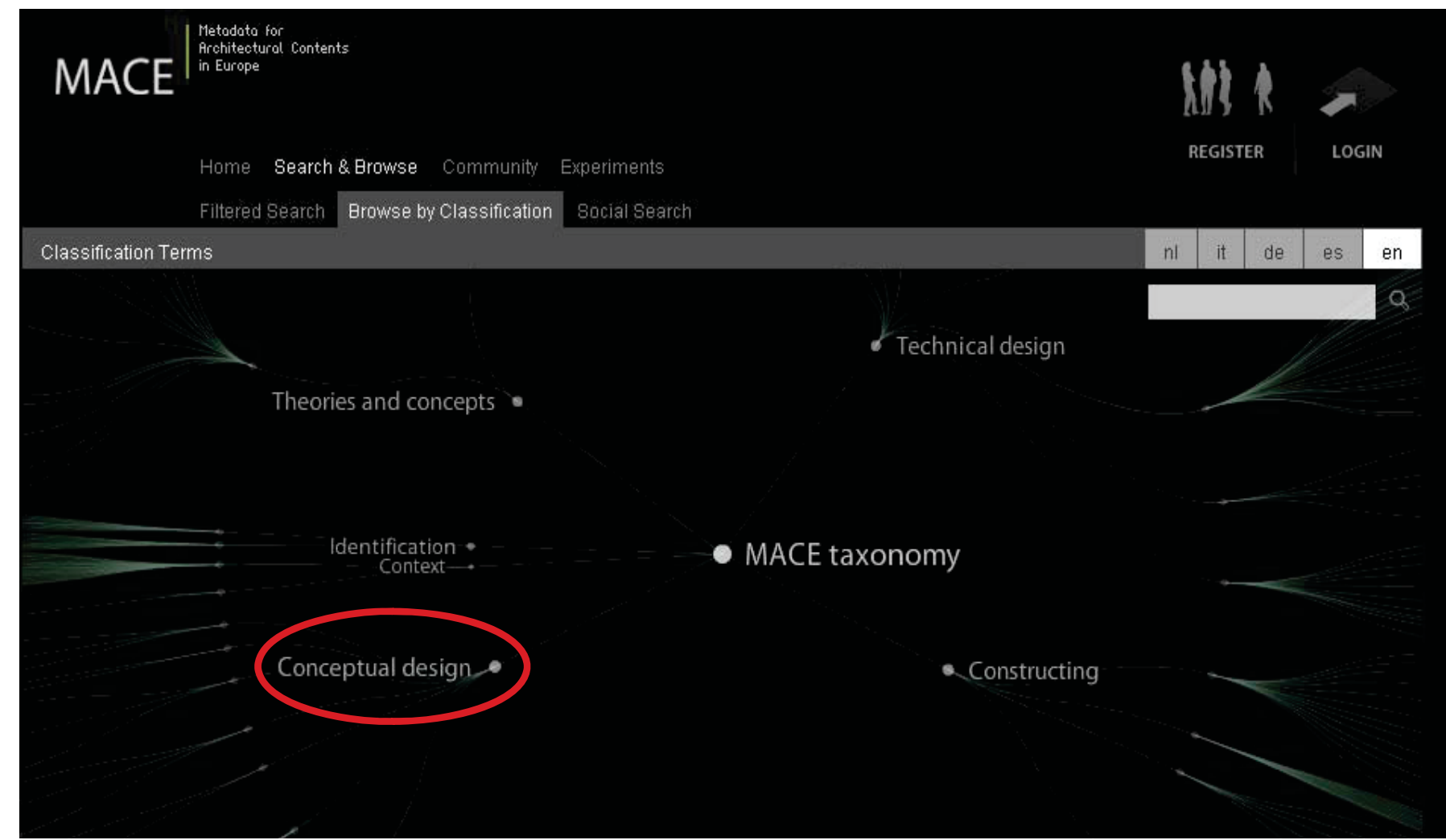

\section{Adriane Borda Almeida da Silva - UFPEL}




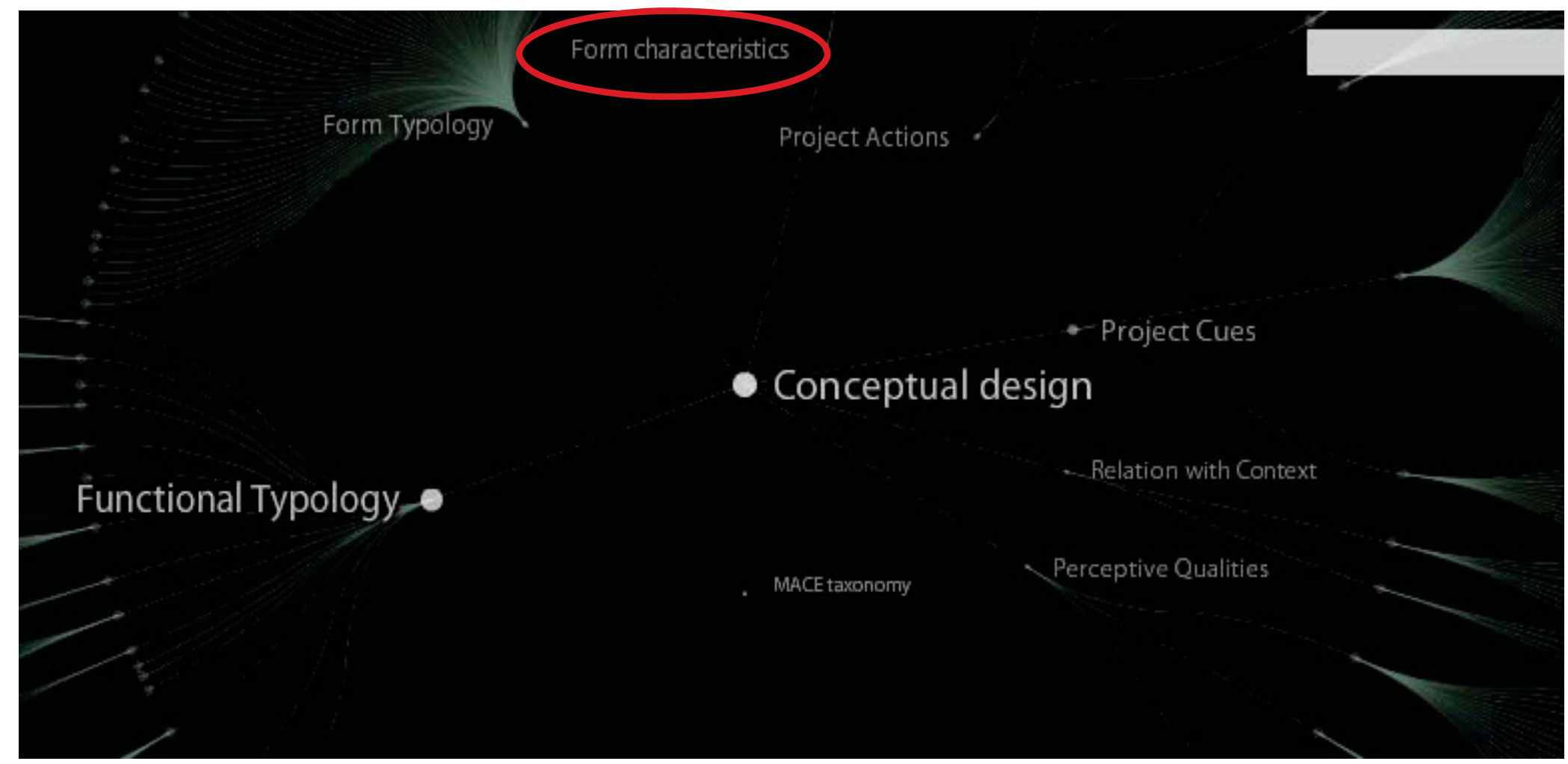




\section{formal composition concepts $\mathbf{b}$}

\section{- Form chararcteristics}




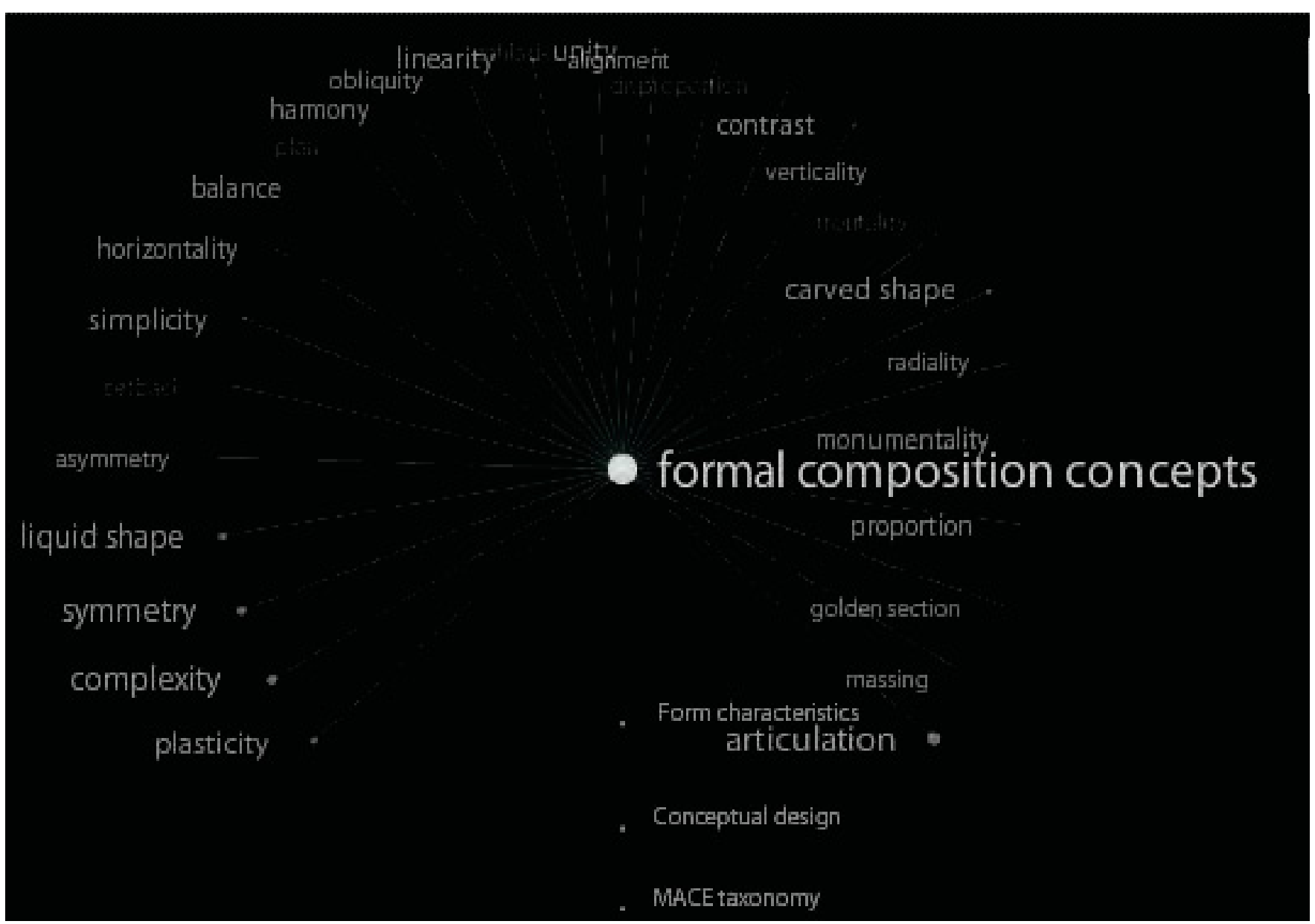

Adriane Borda Almeida da Silva - UFPEL 


\section{Browse by location}



Use our map to browse architectural projects all over the world. 


\section{Browse by competence}

\begin{tabular}{|c|c|c|c|c|}
\hline Knowlebge of fine ants & 2 & 2 & 2 & 2 \\
\hline Knowledge of Kistory & 198 & 205 & 205 & \\
\hline Ablicy w Geate Architectural Design & 580 & SSS & 565 & \\
\hline Ablicy wo math requirenents and cest facters in & 4 & 4 & 4 & 4 \\
\hline Knowledge or Uban Desien & 1Ss & 163 & 164 & 168 \\
\hline Underst peosle/tuilling relations & 537 & ses & $5 S 4$ & S5 \\
\hline Underst of arditectural prefessien & 300 & 313 & 315 & 313 \\
\hline Underst sroject perearstion metheds & 142 & 142 & 144 & \\
\hline
\end{tabular}

Find contents by architectural competence and skill level. 


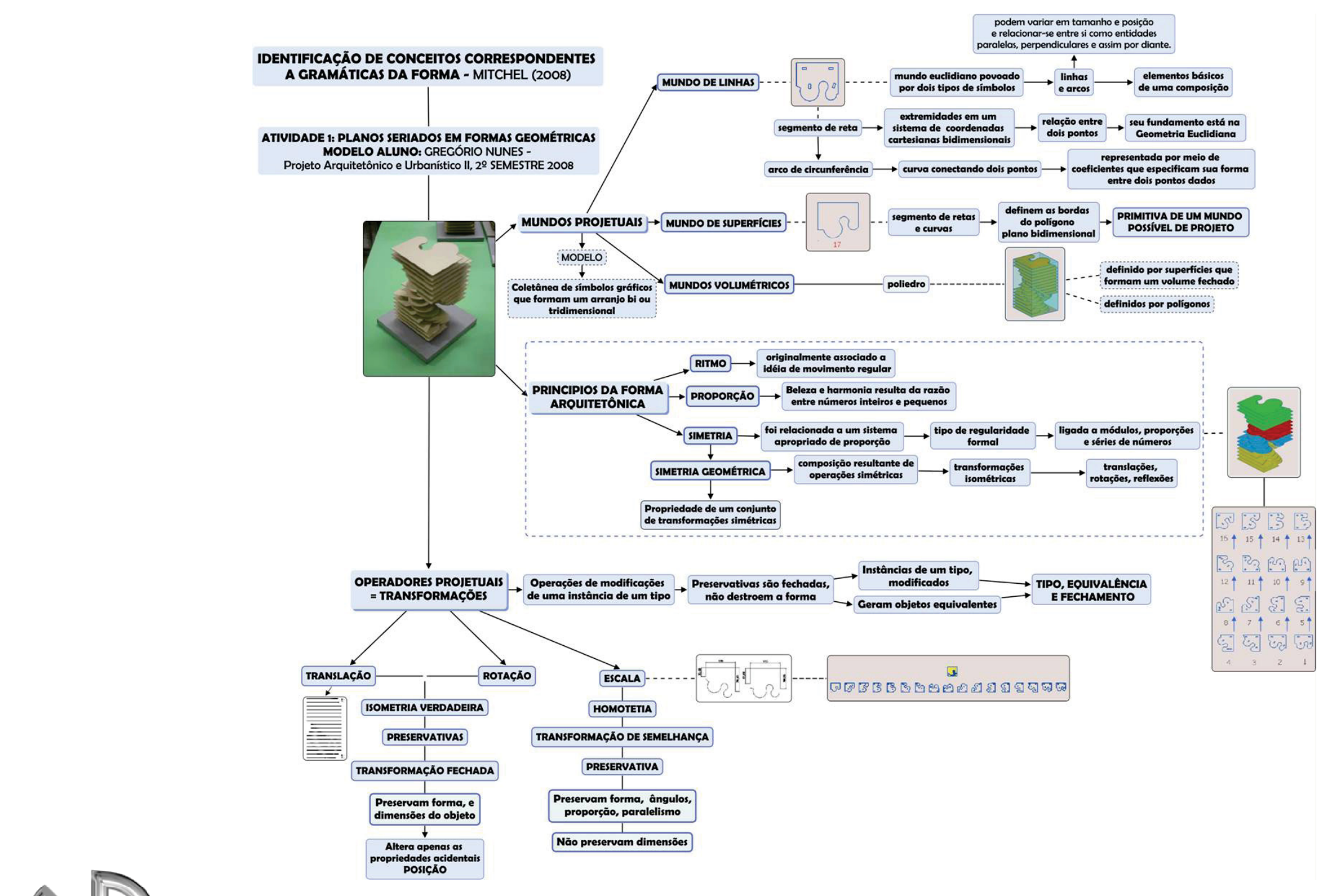

Adriane Borda Almeida da Silva - UFPEL 


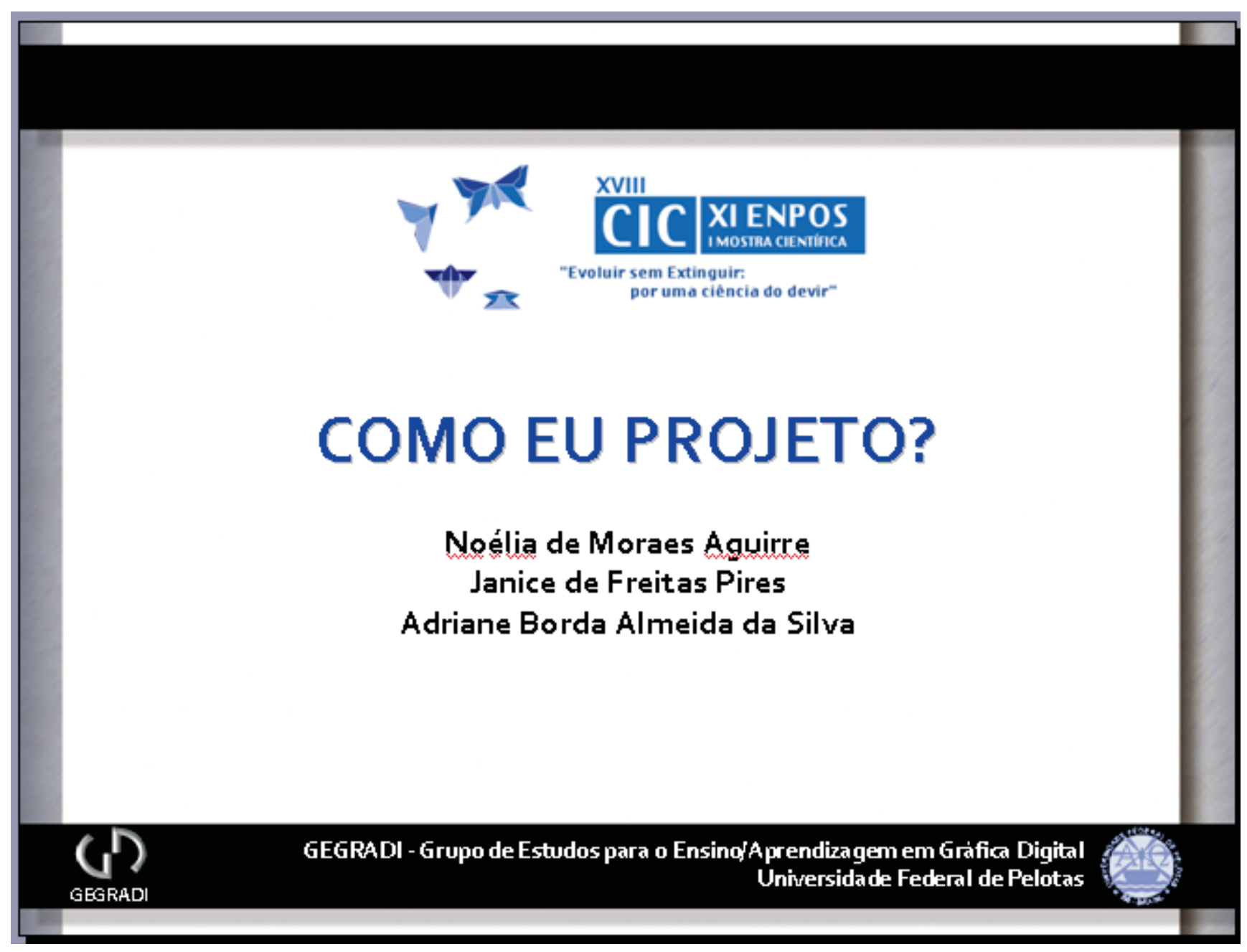

\section{Adriane Borda Almeida da Silva - UFPEL}




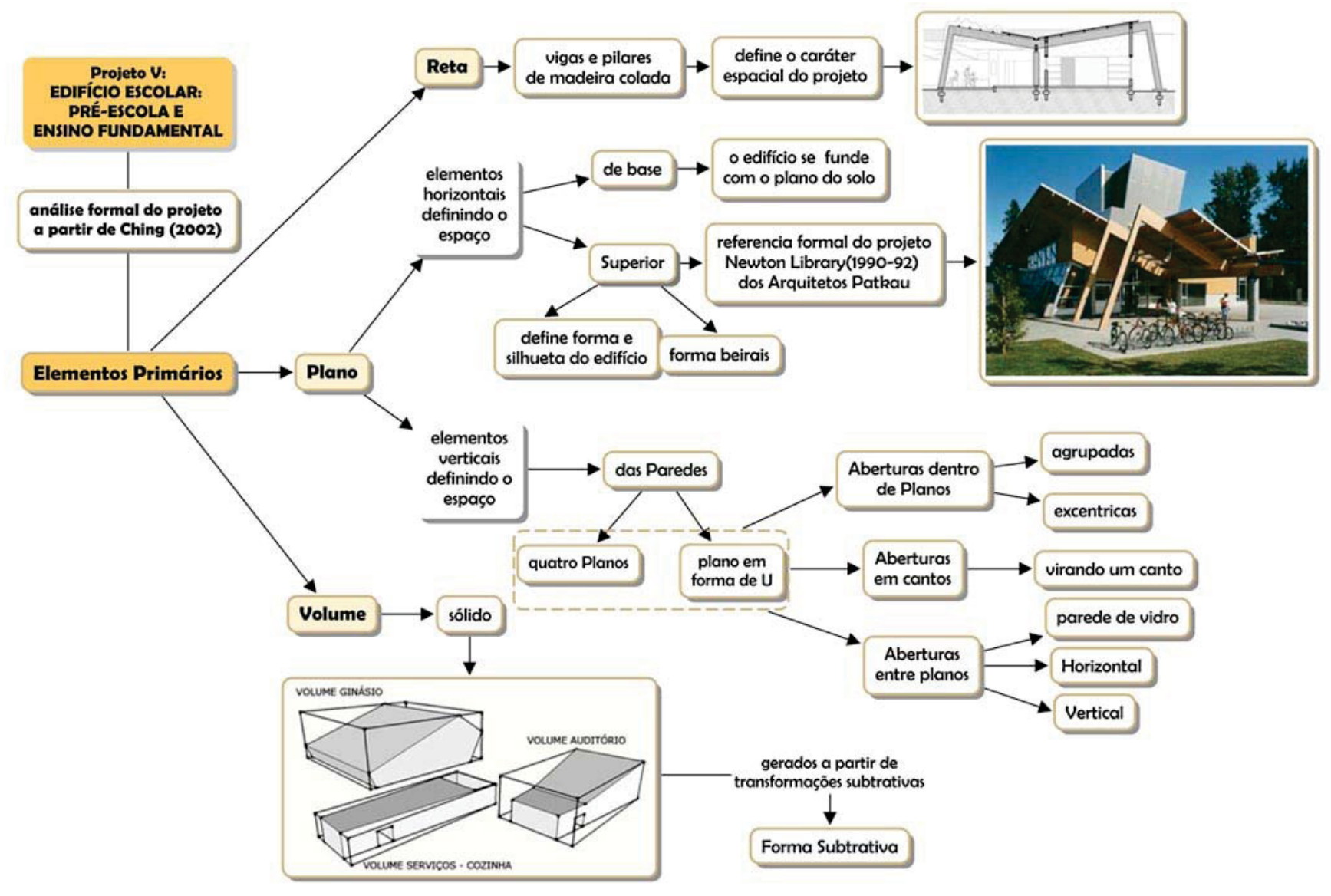

\section{Adriane Borda Almeida da Silva - UFPEL}




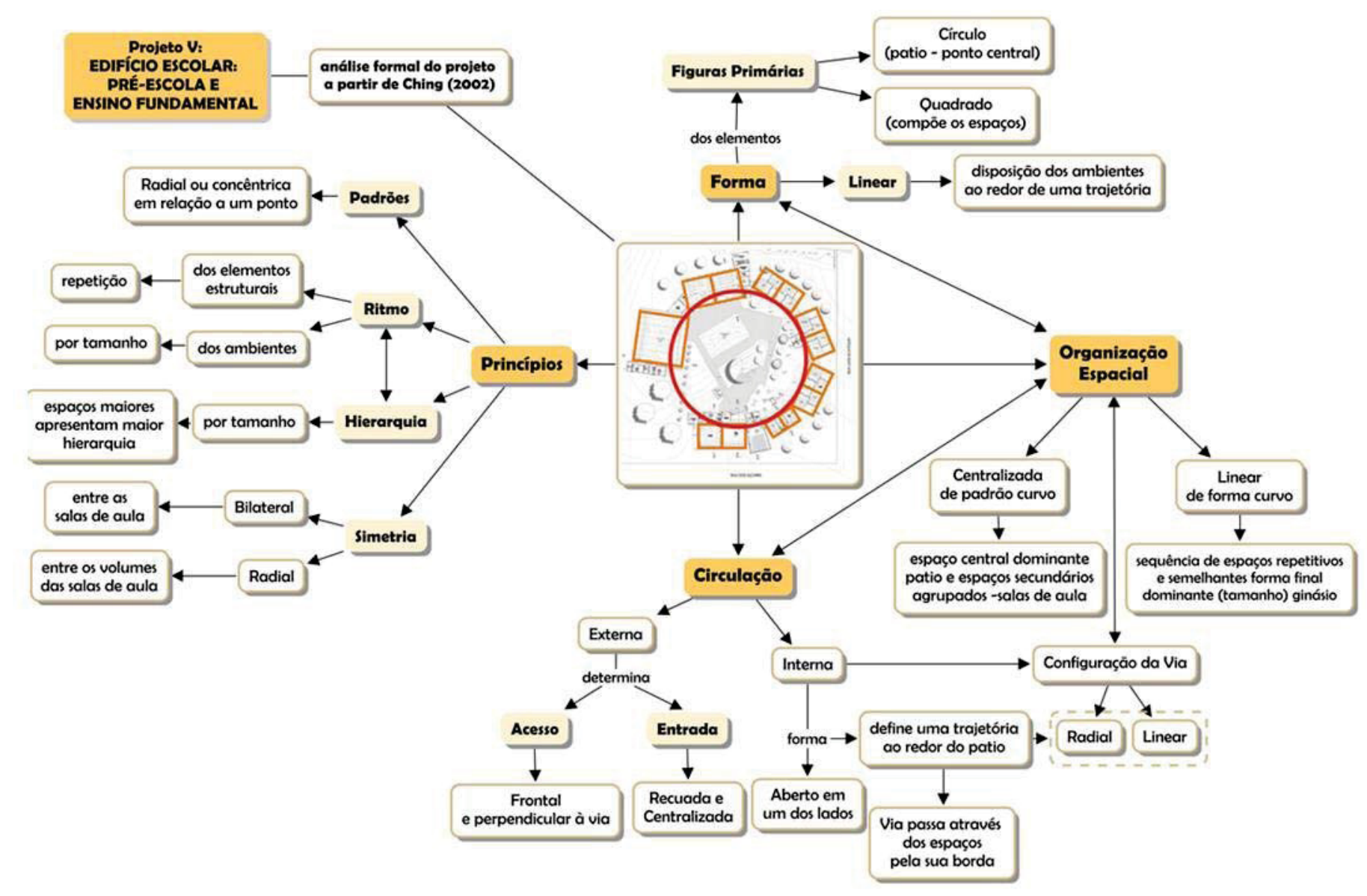

\section{Adriane Borda Almeida da Silva - UFPEL}




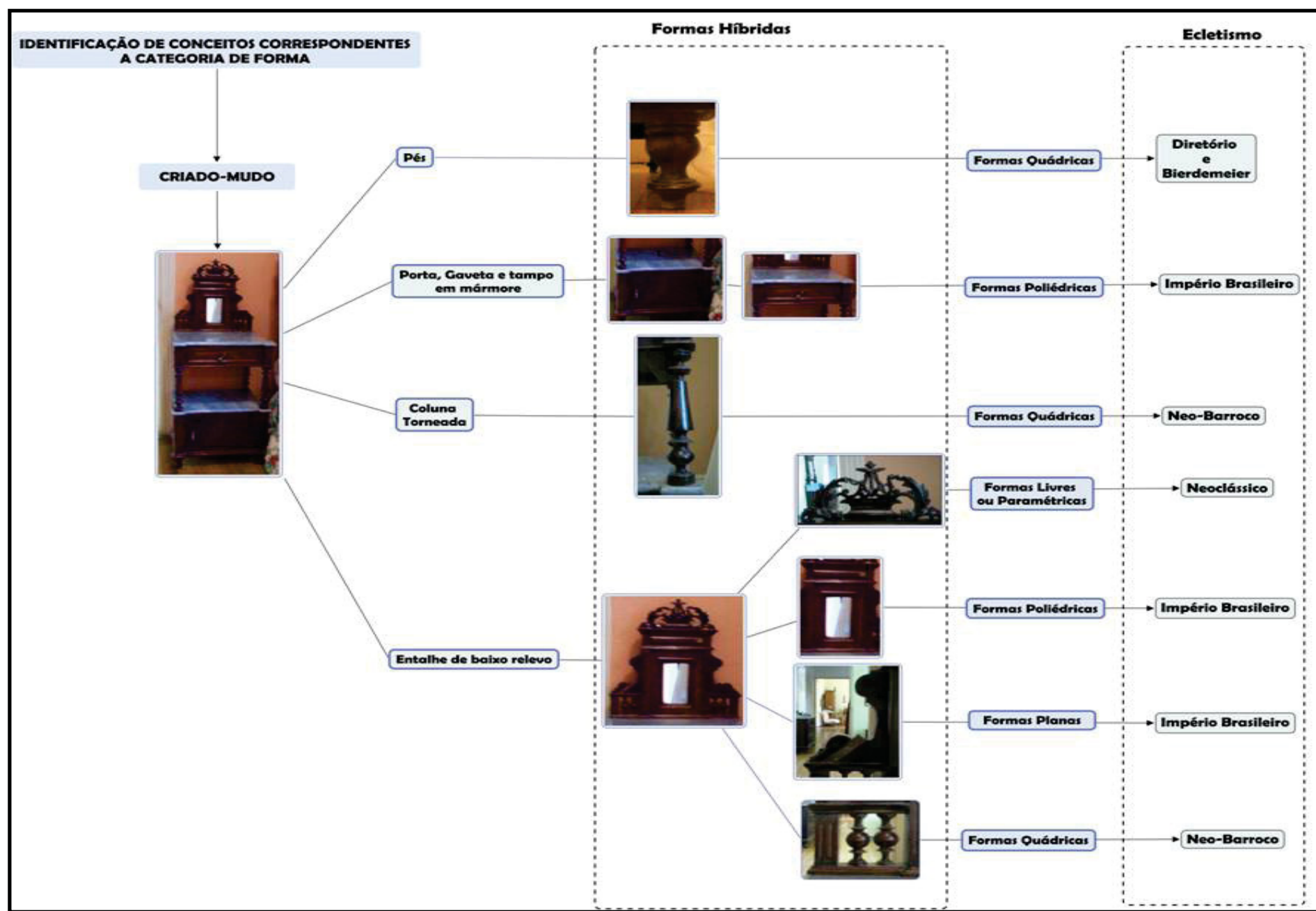

\section{Adriane Borda Almeida da Silva - UFPEL}






\section{Adriane Borda Almeida da Silva - UFPEL}

